\title{
A Study of Relationship between Serum Lipids and Sensorineural Hearing Loss
}

\author{
Authors \\ Dr Anil.H.T ${ }^{1}$, Dr.Shazia ${ }^{2}$ \\ ${ }^{1}$ Professor And Unit Head, Department of ENT,KIMS Hospital, Kempegowda Institute Of Medical \\ Sciences, K.R Road, V.V Puram, Bangalore- 560004 Karnataka, India \\ Email: anilsathwik@gmail.com Contact No: +919341226793 \\ ${ }^{2}$ Junior Resident, Department of ENT, KIMS Hospital, Kempegowda Institute Of Medical Sciences, \\ K.R Road, V.V Puram, Bangalore- 560004 Karnataka, India \\ Email: shazia.darkangel@gmail.com Contact No: +917022140188
}

\begin{abstract}
Objectives: To study the correlation between sensorineural hearing loss and serum level of total cholesterol, triglycerides, HDL (High Density Lipoprotien) and LDL (Low Density Lipoprotien) in patients aged between 30 to 60 years attending otorhinolaryngology department of KIMS.

Materials and methods: 100 adults aged 30-60 years, with SNHL were included in a prospective comparative study and various degree of hearing loss was compared with serum lipids level. Relevant history was obtained. Examination and investigations were conducted.

Results: Statistically significant $(p<0.05)$ mean values of total cholesterol, triglycerides among different degrees of SNHL were found out to be directly proportional in both sexes. In contrast mean values of HDL was inversely proportional.

Conclusion: The study shows significant relationship between serum lipid and various degrees of sensorineural hearing loss. Increase in total cholesterol, triglycerides and LDL, were associated with worsening of hearing levels. Elevated levels of HDL were found to be associated with better hearing levels. Early detection can prevent high risks for both coronary artery disease, hearing loss and vestibular dysfunction.
\end{abstract}

Keywords: Hearing loss, Total Cholesterol, Triglycerides, LDL, HDL.

\section{INTRODUCTION}

Hearing loss is common in patients, but its aetiologies are many. The higher incidence of hearing loss among patients with hyperproteinemia has long been established and is constantly being verified by new studies.

The modern lifestyle poses new challenges on the normal physiological mechanisms of the human body. The adverse impact of a sedentary lifestyle, overweight, unhealthy diet superimposed on a genetic background confers susceptibility to increased circulating lipids. Several studies have demonstrated a relation between hyperlipidemia and hearing disorders, but this point remains controversial.

Various mechanisms by which hyperlipidemia might cause SNHL have been postulated and include atherosclerosis, lipidosis, metabolic disease, aging, hereditary and hypertension ${ }^{1}$. Estimation of serum lipids and their correlation with multiple 
variants and the levels of SNHL may provide an insight into this relationship.

The study was designed to emphasize the need for early detection of hyperlipidemia in SNHL patients who otherwise were not under the care of physicians. In doing so a metabolic abnormality which apparently leads to labyrinthine dysfunction, coronary artery disease and other related illnesses may be better controlled.

\section{MATERIALS AND METHODS}

A prospective observational study was conducted at the department of ENT, Kempegowda Institute of Medical Sciences, Bangalore from April 2015 to March 2016.100 consenting adults of both sexes aged 30-60 years, diagnosed with sensorineural hearing loss of various degrees were included in the study. Those with chronic suppurative otitis media, temporal bone fracture, syphilis, intracranial pathology, noise induced hearing loss, familial hyperlipidemia, diabetes mellitus, chronic alcoholism, on drugs affecting hearing and lipid levels like statins, oral contraceptives and beta blockers were excluded from the study.

All cases were subjected to detailed examination, including general physical, ENT examination and routine investigations were conducted. Hearing loss was defined as an average pure tone threshold $>25$ $\mathrm{dB}$ when measured at frequencies of $125-8000 \mathrm{~Hz}$ for air conduction and 250-4000 for bone conduction. Hearing loss was further classified into mild (26-40dB), moderate(41-70dB), severe(71$90 \mathrm{~dB})$ and profound $(>91 \mathrm{~dB})$ types at the different frequency ranges i.e. low $(250,500 \mathrm{~Hz})$, mid $(1000$. $2000 \mathrm{~Hz})$ and high $(4000,8000 \mathrm{~Hz})$.

\section{Statistical analysis}

Data tabulation and analysis using tests such as unpaired $\mathrm{t}$ test for the parametric data and Chi square test and Mann Whitney $U$ test for non parametric data, along with other statistical tests will be applied based on the need, based on these to draw appropriate conclusions and table recommendations merited.

\section{RESULTS}

Out of 100 cases, 32 patients were having mild SNHL, 30 patients we having moderate SNHL, 32 patients were having moderately severe SNHL and 6 patients were having severe SNHL. Out of 100 cases 12 patients were in the age group of 30-40 years. Majority of the patients, 88 were above the age of 40 years. 66 patients were having male and 34 patients were female. The majority of them were male compared to female groups. The male to female ratio was 1.94:1.24 $(72.77 \%)$ males were having either mild or moderate SNHL. In females $10(58.8 \%)$ were having either moderately severe or severe SNHL.

In our study the relation between total cholesterol and degree of SNHL in both males and females are as proportional. Patients with mild SNHL had least total cholesterol levels of $219 \mathrm{mg} / \mathrm{dl}$ and severe SHNL had 336 in both sexes. (Table1).

\section{TABLE -1}

\begin{tabular}{|l|l|l|l|l|l|}
\hline \multirow{2}{*}{$\begin{array}{l}\text { Degree Of } \\
\text { SNHL }\end{array}$} & \multicolumn{2}{|l|}{ MALE } & \multicolumn{2}{l|}{ FEMALE } & \multirow{2}{*}{ P } \\
\cline { 2 - 5 } & TC & SD & TC & SD & \\
\hline Mild & 219.8 & 26.3 & 219 & 17.9 & \\
\hline Moderate & 248 & 30.9 & 231 & 16.6 & \multirow{2}{*}{$<0.05$} \\
\cline { 1 - 5 } $\begin{array}{l}\text { Moderately } \\
\text { Severe }\end{array}$ & 303 & 12.8 & 274 & 34.7 & \\
\hline Severe & 336 & 5.6 & 336 & 18.9 & \\
\hline Total & 254 & 44.9 & 258 & 41.1 & \\
\hline
\end{tabular}

The relationship between triglycerides and degree of SNL in males and females were similar and proportional to each other. Severe SHNL was noticed at $220.0 \mathrm{mg} / \mathrm{dl}$ in males and $218 \mathrm{mg} / \mathrm{dl}$ in females.

\section{TABLE 2}

\begin{tabular}{|l|l|l|l|l|l|}
\hline \multirow{2}{*}{$\begin{array}{l}\text { Degree of } \\
\text { SNHL }\end{array}$} & \multicolumn{2}{|l|}{ MALE } & \multicolumn{2}{l|}{ FEMALE } & \multirow{2}{*}{ P } \\
\cline { 2 - 5 } & TG & SD & TG & SD & \\
\hline Mild & 185 & 55 & 135 & 16.8 & \\
\hline Moderate & 200 & 37 & 153 & 35 & \\
\cline { 1 - 5 } $\begin{array}{l}\text { Moderately } \\
\text { severe }\end{array}$ & 210 & 12 & 202 & 27 & \\
\hline Severe & 220 & 8.4 & 218 & 15 & \\
\hline Total & 198 & 41 & 180 & 39.6 & \\
\hline
\end{tabular}

The relationship between HDL and degree of SNHL in males and females were inversely proportional to each other. Severe hearing loss was noticed at $25 \mathrm{mg} / \mathrm{dl}$ of HDL. Similar study was noticed in females. 
TABLE 3

\begin{tabular}{|c|c|c|c|c|c|}
\hline \multirow{2}{*}{$\begin{array}{ll}\text { Degree } & \text { of } \\
\text { SNHL }\end{array}$} & \multicolumn{2}{|c|}{ MALE } & \multicolumn{2}{|c|}{ FEMALE } & \multirow[t]{2}{*}{$\mathrm{P}$} \\
\hline & HDL & SD & HDL & SD & \\
\hline Mild & 36.8 & 4 & 37 & 2.2 & \multirow{5}{*}{$<0.05$} \\
\hline Moderate & 34 & 2.9 & 34 & 2 & \\
\hline $\begin{array}{l}\text { Moderately } \\
\text { severe }\end{array}$ & 26 & 2.2 & 30 & 6 & \\
\hline Severe & 25 & 7 & 26 & 2.8 & \\
\hline Total & 32 & 5.4 & 30 & 5.5 & \\
\hline
\end{tabular}

\section{DISCUSSION}

The result of this study shows that there are significant alterations in the lipid profiles among different degree of sensorineural hearing loss. The number of male and female patients studied by Lee FS et $\mathrm{al}^{1}$ were 128 and 89 respectively. Among the sensorineural hearing loss patients the male : female ratio was 1.44:1.The number of male and female patients studied by Suzuki K et al ${ }^{1}$ were 607 and 317 respectively and the male: female ratio was 1.91:1. In our study this ratio was $1.94: 1$. This is consistent with the study done by others.

Lee FS et $\mathrm{al}^{2}$ in their study of 217 patients found mean total cholesterol values to be $221.83 \pm 20$ $\mathrm{mg} / \mathrm{dl}$. Jones NS et $\mathrm{al}^{3}$ in their study on 85 patients found mean total cholesterol values to be $225.77 \mathrm{mg} / \mathrm{dl}$. In the present study the mean cholesterol values were found to be $255.80 \mathrm{mg} / \mathrm{dl}$. The values were comparable with the above studies. Among the male population of the study group, Suzuki K et $\mathrm{al}^{2}$ found mean total cholesterol to be $202 \pm 32.5$ and $210.9 \pm 39.1 \mathrm{mg} / \mathrm{dl}$ in the female population. In the present study the mean total cholesterol were $254.55 \pm 44.91$ and $258.24 \pm 41.18$ $\mathrm{mg} / \mathrm{dl}$ in the males and females respectively.

The mean total cholesterol values among various groups of SNHL in both males and females in the above studies were statistically significant and directly proportional to the degree of SNHL in accordance with the above mentioned studies. Increase in total cholesterol showed worsening of hearing.

Lee FS et $\mathrm{al}^{1}$ in their study found the mean HDL values were found to be $32.12 \pm 6.81 \mathrm{mg} / \mathrm{dl}$. Suzuki K et $\mathrm{al}^{1,4}$ found mean HDL to be $54.6 \pm 14$ and $66.5 \pm 15 \mathrm{mg} / \mathrm{dl}$ in the male and female patients respectively. The present study revealed mean HDL in male and female patients to be $32.94 \pm 5.49$ and $30.53 \pm 5.52 \mathrm{mg} / \mathrm{dl}$ respectively. These values were statistically significant and showed a negative correlation in the hearing loss. Increase in HDL showed better hearing.

Comparing the various lipid parameters with NCEP Adult treatment Panel III guidelines it can be noted that total cholesterol triglycerides and LDL in both sexes were found to be elevated in an ascending order from mild to severe degrees of hearing loss and lower in cases of moderately severe and severe hearing loss 5 .

Friedrich $\mathrm{G}$ et $\mathrm{al}^{5}$ found no change in serum triglyceride or total cholesterol concentrations in patients with neuro-otological symptoms such as dizziness, tinnitus or SNHL. These patients had a significantly elevated LDL concentration and ratio of LDL/HDL in serum. They suggested an association between atherosclerosis and inner ear dysfunction.

In the present study the total cholesterol triglycerides and LDL levels were found to be statistically significant and their increase showed worsening of hearing. The HDL levels were high in mild SNHL compared to severe SNHL, which is similar to the above study.

Gates GA et $\mathrm{al}^{6}$ reported no correlation of hearing levels with total cholesterol or triglycerides, but HDL in women negatively correlated with hearing levels.

In the present study there was a positive correlation of hearing levels with cholesterol triglyceride and LDL in both males and females. But HDL was negatively correlated with hearing levels in both males and females.

Oxidative LDL is believed to play an important role in the events associated with the initiation of atherosclerosis ${ }^{7,8}$. Uptake of oxidised LDL via recognition of the modified apolipoprotien $\mathrm{B}$ at the macrophage scavenger receptors leads to the formation of lipid laden foam cells in vitro, resembling those in the fatty streak. HDL has been shown to prevent oxidative modification of LDL in vitro, as well as in vivo ${ }^{9,10}$. 
These results suggests that a low serum HDL and high LDL is associated with atherosclerosis related micro circulatory disturbances of the cochlear vasculature and increased susceptibility of the cochlea to noise. When combined with daily exposure to noise, these changes can lead to hearing loss. Low cholesterol diet and anti-lipid therapy can provide significant improvement by way of lowered tinnitus intensity and improvement in average hearing thresholds in NIHL patients ${ }^{10}$.

\section{CONCLUSION}

The study shows a significant relationship between serum lipids and various degrees of sensorineural hearing loss. Increase in total cholesterol, triglycerides and LDL, were associated with worsening of hearing levels. Elevated levels of HDL were found to be associated with better hearing levels. In the light of the study there is a need for early detection of patients with hyperlipoprotienemia who are at risk for atherosclerosis as they are candidate for both coronary artery disease, hearing loss and vestibular dysfunction.

\section{ABBREVIATIONS}

SNHL : Sensorineural hearing loss

LDL : low density lipoprotein

HDL: High density lipoprotein

TC: Total Cholesterol

TG: Triglyceride

SD: Standard deviation

\section{REFERENCES}

1. Suzuki K, Kaneko M, Murai K. Influence of serum lipids on auditory function. The Laryngoscope. 2000 Oct 1;110(10):1736-8.

2. Lee FS, Matthews LJ, Mills JH, Dubno JR, Adkins WY. Analysis of blood chemistry and hearing levels in a sample of older persons. Ear and hearing. 1998 Jun 1;19(3):180-90.

3. Jones NS, Davis A. A prospective case-controlled study of patients presenting with idiopathic sensorineural hearing loss to examine the relationship between hyperlipidaemia and sensorineural hearing loss 1. Clinical Otolaryngology \& Allied Sciences. 1999 Dec 1;24(6):531-6.

4. Spencer JT. Hyperlipoproteinemias in the etiology of inner ear disease. The Laryngoscope. 1973 May 1;83(5):639-78.

5. Expert Panel on Detection E. Executive summary of the Third Report of the National Cholesterol Education Program (NCEP) expert panel on detection, evaluation, and treatment of high blood cholesterol in adults (Adult Treatment Panel III). Jama. 2001 May 16;285(19):2486.

6. Friederich G, Pilger E. Lipoproteins in cochleovestibular disorders. Arch Otolaryngol. 1981;232:101-5.

7. Gates GA, Cobb JL, D'Agostino RB, Wolf PA. The relation of hearing in the elderly to the presence of cardiovascular disease and cardiovascular risk factors. Archives of Otolaryngology-Head \& Neck Surgery. 1993 Feb 1;119(2):156-61.

8. Saito T, Sato K, Saito H. An experimental study of auditory dysfunction associated with hyperlipoproteinemia. Archives of otorhino-laryngology. 1986 Sep 1;243(4):2425.

9. Gratton MA, Wright CG. Alterations of inner ear morphology in experimental hypercholesterolemia. Hearing research. 1992 Aug 1;61(1-2):97-105.

10. Ullrich D, Aurbach G, Drobik C. A prospective study of hyperlipidemia as a pathogenic factor in sudden hearing loss. European archives of oto-rhino-laryngology. 1992 Jan 1;249(5):273-6. 